\title{
Obesity Awareness and Nutrition Behavior of School Children in Uşak Province, Republic of Turkey
}

\author{
Mustafa Akil ${ }^{*}$, Elif Top ${ }^{1}$ \\ ${ }^{1}$ Faculty of Sport Sciences, University of Usak, Usak, Turkey
}

\begin{abstract}
This study aimed to investigate the correlation between the awareness of children about obesity and their nutritional behaviors. Obesity Awareness Scale (OAS) and the Food Behavior Scale (FBS) were utilized for the data collection in the present study. The subjects were 699 male and female school children. Analyisis showed a significant correlation between the sub-dimensions of OAS and the total scores of FBS $(p<0.05)$. There were significant differences on levels of OAS and FBS depending on educational status $(\mathrm{p}<0.05)$. The total score of FBS was also differ significantly between the healthy participants and the overweight ones $(\mathrm{p}<0.05)$. The results showed that there is a positive correlation between the nutritional behaviors and obesity awareness; being or not being engaged in sports does not have an effect in the study subject's obesity awareness and nutrition behaviour; the nutritional behaviours and obesity awareness are depending on the educational level of the mother and the father and the subjects who have good nutritional behaviors, also have normal BMI (Body Mass Index).
\end{abstract}

Keywords: children, obesity, nutrition, sport

\section{INTRODUCTION}

Previous studies suggested that the individuals who are obese during their childhood and adolescence tend to be obese in their adulthood as well (Barlow 2007). Although it is recommended that obesity should be prevented in the childhood period, the antiobesity programs available are far from being adequate (Whitlock et al. 2010). The lifestyle habits are acquired at early ages and the necessary interventions should be done in order to prevent the development of the childhood obesity (Hansson et al. 2016). Although it is acknowledged that various interventions should be done during the childhood, the opinions concerning the extent of the effects of the changes in the nutritional behaviors (Döring et al. 2014) are not clear (Lakshman et al. 2013).

Children and adolescents are prone to the effects of malnutrition. The unhealthy nutritional habits are acquired especially in the school ages and such habits may be maintained throughout life. Skipping meals may result in the consumption of food products that are low in nutritional value and high in calories (Galczak-Kondraciuk et al. 2018). The increase in the consumption of high-calorie foods and the decrease in the physical activity diminish the probability of developing and maintaining a balanced nutrition and a healthy lifestyle among children (Ahrens et al.
2006). Previous studies suggest that children at the school ages do not consume the recommended amounts of fruit and vegetables, but they frequently consume fast food and energy drinks which are high in energy, fat, and salt (DemoryLuce 2005; Pérez et al. 2007; Zaborskis et al. 2012). Moreover evidence on the correlation between the consumption of salty, sugary, fatty food, and carbonated beverages with obesity has been determined (Boumtje et al. 2005; Newby 2007).

Since nutrition is a socially learned behavior, the effect of the environment is important (Story et al. 2002). In addition, friends constitute one of the most important factors for adolescents. Since its effect on children is important, it is necessary to know about the effects of nutrition and exercise on their health behaviors (Story et al. 2002; Hern et al. 1998). However, the role of the family is also important since unhealthy nutritional behavior of the children may result from the family's unhealthy lifestyle (Novilla et al. 2006).

Today, while the physical activity level of children is decreasing, their sedentary lifestyle is on the increase. Imparting healthy living behaviors to children requires a multifactorial approach including the children and their families. Thus, the purpose of the present study is to determine the obesity awareness level of the children

"Corresponding Author: email: mustafa.akil@usak.edu.tr 
who are engaged in sports and those who are not, and to investigate whether enggagement in sporting activities correlates to their nutritional behaviors or not.

\section{METHODS}

\section{Design, location, and time}

The study design was of female and male students studying in a public secondary school in the province of Uşak, Republic of Turkey. A total number of 699 participants, $362(51.70 \%$; $12.00 \pm 1.07$ years of age) of which were female and $337(48.3 \% ; 12.01 \pm 1.10$ years of age) male, were evaluated. The students included in the study were divided into two groups, the first of which comprising 264 students who were not engaged in physical activity and the second comprising 435 students performing physical activities 3 or more days a week. The required permissions for the present study were obtained from Uşak Provincial Directorate of National Education.

\section{Data collection}

The data was collected by face-to-face interview. The heights of the children were measured with their shoes and hair clips removed, their shoulders squared, their hands at their sides, knees not bent, the heels juxtaposed, and in a position leaning against the wall. The body weight was measured with automatic reporting feature of the body analysis device model and make of IOI353. The body weight $/$ height $^{2}$ formula was used in determining the BMI. The percentile curves determined for Turkish children were used for determining the overweight status. When the BMI was examined based on the gender and age, 95 percentile and over was defined as obese, the interval between 85 and 95 percentiles was defined as overweight, and the interval between 5 and 85 percentiles was defined as having normal weight. Based on the criterias, 653 (94\%) students had normal weight, 31 (4\%) were overweight, and 15 (2\%) were obese.

Body measurement was carried with Jawon make body composition analyzer (model IOI-353). The device conducts analysis one leg through to the other, and has a clean steel surface (Chen et al. 2014). The weight was measured and recorded with a precision of $0.1 \mathrm{~kg}$ while the participants were wearing light clothes with bare oot.

The Obesity Awareness Scale (OAS) used in the present study was developed by Allen (2011), and it comprises 23 items and three subdimensions. The sub-dimensions of the scale are a) the obesity awareness sub-dimension ( 8 items), b) the nutrition sub-dimension (7 items), and c) the physical activity sub-dimension ( 8 items). The scale has the structure of a negative-to-positive 4-point Likert scale. The internal consistency coefficient for the entire scale was stated to be $\alpha=0.80$ (Allen 2011). The scale was adapted to Turkish by Kafkas and Özen (2014). When it was examined by means of the explanatory factor analysis, the item loads of the obesity awareness scale were found to be in the interval of 0.42 0.72 . The scale comprises a total number of 21 items under three sub-dimensions. The general internal consistency Cronbach $\alpha$ value was found to be at a good level with 0.87 , and it was considered to be a good scale for Turkish children (Kafkas \& Özen 2014). The Cronbach $\alpha$ internal consistency coefficients were investigated in the present study, and the total value for the obesity awareness scale was found to be 0.78 , and the values for the sub-dimensions were found to be in the interval of 0.73-0.62.

In determining the food behaviors, the Food Behaviors Scale (FBS), which was developed by Edmundson et al. (1996) and adapted to Turkish children by Öztürk and Erdoğan (2010), was used. The scale comprised 14 different question items including low-fat and high-fat, and salty and salt-free illustrated and optional two foodstuffs, which were intended to determine the food consumption of the children. The students were asked to mark the one they ate more among the comparable two foodstuffs in each question item. The items of the scale receive a value of -1 for each unhealthy foodstuff and +1 for each healthy foodstuff. The total points can be between -14 and +14 . A high total point scored in the scale shows healthy nutritional habits. The reliability of the scale has been stated to be $\mathrm{r}=0.76$ (Edmundson et al. 1996; Öztürk \& Erdoğan 2010). The food behaviors scale used in the present study was examined by KR20 test, and the result was found to be 0.76 . The study was also approved by the Social and Human Sciences Scientific Research and Publications Ethics Council of Uşak University (2018-34).

\section{Data Analysis}

SPSS 25.0 statistical software package was employed in the analysis of the data. Cronbach Alpha internal consistency coefficient was examined in order to measure the reliability of the scales. The data obtained in the study were found to have a normal distribution. After it was examined by means on "One-Way Anova" whether there was a difference between the mother's educational level, the father's educational level and 
the BMI, the Scheffe Test, which is a Post-Hoc test, was employed in order to see the differences between the groups. The correlations between the Physical Activity Levels of the children, their Obesity Awareness Levels and their Nutrition Behaviors were assessed by Pearson Correlation method. In order to determine whether the groups differed depending on the gender and being or not being actively engaged in sports, Independent Sample t-test was employed. The statistical significance level was accepted $\mathrm{p}<0.05$.

\section{RESULTS AND DISCUSSION}

When the obesity awareness levels of the female and male students were examined, no statistically significant differences were found in the total score or in the sub-dimensions $(\mathrm{p}>0.05$; Table 1), but the female student's scores were higher than those of the male students. A number of previous studies have also suggested that female children usually prefer healthier foods and consume more fruit and vegetables compared to males (Reynolds et al. 1999; Macaux 2001; Cooke \& Wardle 2005). Wardle et al. (2004) suggested that the reason for that difference was the fact that the energy requirements of males were higher compared to females, and that they liked more the foodstuff with intense energy content (Wardle et al. 2004). This situation can also be explained by the fact that female students are more self-conscious concerning their body shape and thus pay more attention to what they eat compared to the male students.

The fact that females attach more importance to their physical appearance during their adolescence period might have brought about that level of awareness. The prevalence of obesity was found to be higher in girls than in boys in the United States of America (Must et al. 1991), while the prevalence of obesity was found to be higher among boys than in girls in the Middle
East region (Al-Almaie 2005). Prevalence of obesity is higher among the boys compared to girls in developing countries, which may be resulting from the different cultural habits, from different attitudes towards the diet and physical activity (Mirmiran et al. 2010), and from the factors of race and ethnic background (Cheung et al. 2016). The fact that a study conducted in Turkey found the boys to be a group under more risk compared to girls in terms of their nutritional habits (Demirezen \& Coşansu 2005) is of importance in terms of supporting the present study. That no statistically significant difference depending on gender was found between the groups in the present study may have resulted from the fact that the majority of the subjects were engaged in sports.

When the obesity awareness levels and the FBS scores of the participants who are engaged in sports and those who are not were compared, no statistically significant difference was found in the total score or in the sub-dimensions $(\mathrm{p}>0.05$; Table 2). When the sub-dimensions of obesity awareness and the total FBS scores were examined depending on the variable of the educational levels of the mother and father, it was found that the obesity awareness level of the children inversely correlated to the educational levels of the mother and the father, and that their food behaviors improved depending on the increased educational levels of the mother and the father $(\mathrm{p}<0.05$; Table $3,4,5,6)$. Although this result may seems to be contradictory, studies have found firm correlation between the childhood overweight and the poverty (Boumtje et al. 2005), the low family income (Gray et al. 2007) and the low educational level of the mother and father (Güven et al. 2008; $\mathrm{O}^{\mathrm{ec}}$ Dea \& Wilson 2006). In addition a number of studies have shown that the socioeconomic status (Rosas et al. 2011) and the high educational level of the mother and father (Isabela da Costa et al. 2003; Padez et al. 2005) is a risk factor for childhood obesity. The fact that access to ready food

Table 1. Comparison of the obesity awareness scale and food behavior scale scores of the female and male students

\begin{tabular}{llcccccc}
\hline \multicolumn{1}{c}{ Variables } & Gender & $\mathrm{n}$ & Mean & $\mathrm{Sd}$ & $\mathrm{t}$ & $\mathrm{df}$ & $\mathrm{p}^{*}$ \\
\hline Obesity awareness & Female & 362 & 21.63 & 3.54 & 1.474 & 697 & 0.141 \\
& Male & 337 & 21.21 & 3.93 & & & \\
Nutrition & Female & 362 & 21.02 & 3.35 & 0.722 & 681 & 0.471 \\
& Male & 337 & 20.83 & 3.63 & & & \\
Physical activity & Female & 362 & 15.45 & 2.45 & 1.769 & 697 & 0.077 \\
& Male & 337 & 15.10 & 2.68 & & & \\
FBS total points & Female & 362 & 1.64 & 5.17 & 1.148 & 697 & 0.251 \\
& Male & 337 & 1.18 & 5.22 & & & \\
\hline
\end{tabular}

df: Degrees of Freedom; Sd: Standart Deviation; *Independent t-test. 
Table 2. Comparison of the Obesity Awareness Scale and Food Behavior Scale scores of the participants who are engaged in sports and those of the participants (yes) and who are not (no)

\begin{tabular}{lccccccc}
\hline \multicolumn{1}{c}{ Variables } & Are you aged in sports? & $\mathrm{n}$ & Mean & $\mathrm{Sd}$ & $\mathrm{t}$ & $\mathrm{df}$ & $\mathrm{p}^{*}$ \\
\hline Obesity awareness & No & 265 & 21.69 & 3.62 & 1.581 & 698 & 0.114 \\
\multirow{4}{*}{ Nutrition } & Yes & 435 & 21.22 & 3.93 & & & \\
\multirow{4}{*}{ Physical activity } & No & 265 & 20.70 & 3.14 & -1.184 & 698 & 0.237 \\
& Yes & 435 & 21.03 & 3.81 & & & \\
FBS total points & No & 265 & 15.13 & 2.55 & -1.003 & 698 & 0.316 \\
& Yes & 435 & 15.34 & 2.68 & & & \\
& No & 265 & 0.94 & 4.86 & -1.898 & 698 & 0.058 \\
\hline df: Degrees of Freedom: Sd: Standart Devition; *Independent t-test & & & & & &
\end{tabular}

df: Degrees of Freedom; Sd: Standart Deviation; *Independent t-test.

becomes easier and the consumption increases depending on the increasing socioeconomic status has been suggested as a reason for that (Rosas et al. 2011). The study conducted by Crawford et al. (2001) is of importance in terms of producing both results. The differences found when the race and socioeconomic status were examined were linked to the cultural and environmental factors (Crawford et al. 2001). These findings are of importance in terms of supporting and explaining the present study. The most notable finding in the present study is that there is a correlation between the sub-dimensions of the obesity awareness level and the food behaviors.

When the correlation between the sub-dimensions of obesity awareness level and the food behaviors was investigated, a statistically significant positive correlation was found between the obesity awareness $(0.077 *)$ and physical activity and the sub-dimensions of nutrition $\left(-078^{*}\right.$; $\mathrm{p}<0.05)$. When all these findings are considered together, it can be said that although the application of only the knowledge-based curricula in order to prevent obesity among school-age children is effective in changing nutritional habits and cre- ating awareness, this effect is minute (Atkinson $\&$ Nitzke 2001). In the curricula where the physical activity and nutrition are jointly used, only temporary changes take place in the weight or in the behaviors (Lytle 2009). Moreover, it has also been suggested that the dimensions of education, government policy, behavioral changes, physical activity and peer influences should also be considered (Stock et al. 2007). It is also necessary to add the education of the mother and the father, as well as the environmental and cultural behaviors to the stated factors, because the parents present the child with an effective environment for the food behaviors in the early period of the life. The nutritional habits of the children are affected by the nutritional habits of the family (Scaglioni et al. 2008). Hood et al. (2000) suggested that the increase in the unhealthy nutritional habits of the family accelerates the increase in the body fat rates in children. The environment created by parents for their children can increase their unhealthy food behaviors as much as it can promote the healthy food behaviors.

Balanced nutrition and regular physical activity are among the most important factors in

Table 3. The results of the ANOVA test on the obesity awareness scale and food behavior scale depending on the variable of the educational level of mother

\begin{tabular}{llrrrrc}
\hline \multicolumn{1}{c}{ Variables } & Source & \multicolumn{1}{c}{ df } & \multicolumn{1}{c}{ SS } & \multicolumn{1}{c}{ MS } & \multicolumn{1}{c}{ F } & \multicolumn{1}{c}{ p $^{*}$} \\
\hline Obesity awareness & Intergroup & 3 & 303.98 & 101.32 & 8.110 & 0.000 \\
& Intragroup & 598 & $7,471.17$ & 12.49 & & \\
Nutrition & Intergroup & 3 & 52.13 & 17.38 & 1.375 & 0.249 \\
& Intragroup & 598 & $7,558.36$ & 12.64 & & \\
Physical activity & Intergroup & 3 & 63.86 & 21.29 & 3.334 & 0.019 \\
& Intragroup & 598 & $3,818.07$ & 6.39 & & \\
FBS total points & Intergroup & 3 & 651.94 & 217.31 & 7.933 & 0.000 \\
& Intragroup & 598 & $16,382.08$ & 27.40 & & \\
\hline
\end{tabular}

SS: Sum of Squares; MS: Mean Square; *significant in $\mathrm{p}<0.05$ 
Table 4. The Results of the post-hoc scheffe test on the sub-dimensions of obesity awareness scale and food behavior scale depending on the variable of the educational level of the mother

\begin{tabular}{lllcc}
\hline \multicolumn{1}{c}{ Sub-dimensions } & & Educational level & $\overline{\mathrm{x}}$ & $\mathrm{p}^{*}$ \\
\hline Obesity awareness & Primary school & High school & $1.555^{*}$ & 0.002 \\
& Middle school & High school & $1.783^{*}$ & 0.001 \\
& Middle school & University & $1.171^{*}$ & 0.048 \\
Physical activity & High school & University & $-0.779^{*}$ & 0.048 \\
FBS total points & University & Primary school & $2.495^{*}$ & 0.001 \\
& & Middle school & $2.474^{*}$ & 0.001 \\
& & High school & $1.700^{*}$ & 0.032 \\
\hline
\end{tabular}

FBS: Food behaviour scale; ANOVA followed by Scheffe test multiple range test. *significant in $\mathrm{p}<0.05$

Table 5. The results of the ANOVA test concerning the effects of the educational level of father on the Obesity Awareness Scale and Food Behavior Scale

\begin{tabular}{llrrrcc}
\hline \multicolumn{1}{c}{ Variables } & Source & $\mathrm{df}$ & $\mathrm{SS}$ & $\mathrm{MS}$ & $\mathrm{F}$ & $\mathrm{p}$ \\
\hline Obesity awareness & Intergroup & 3 & 116.62 & 38.87 & 3.008 & 0.030 \\
& Intragroup & 606 & $7,831.84$ & 12.92 & & \\
Nutrition & Intergroup & 3 & 45.33 & 15.11 & 1.207 & 0.306 \\
& Intragroup & 606 & $7,587.42$ & 12.52 & & \\
Physical activity & Intergroup & 3 & 21.17 & 7.06 & 1.097 & 0.350 \\
& Intragroup & 606 & $3,897.46$ & 6.43 & & \\
FBS total points & Intergroup & 3 & 667.22 & 222.41 & 8.398 & 0.000 \\
& Intragroup & 606 & $16,049.31$ & 26.48 & & \\
\hline
\end{tabular}

FBS: Food behaviour scale; SS: Sum of Squares; MS: Mean Square; *significant in $\mathrm{p}<0.05$

Table 6. The results of the post-hoc Scheffe test on the OAS sub-dimensions and the total FBS score depending on the variable of the educational level of the father

\begin{tabular}{lllcc}
\hline \multicolumn{1}{c}{ Sub-dimension } & & School & $\overline{\mathrm{x}}$ & $\mathrm{p}^{*}$ \\
\hline Obesity awareness & Middle school & University & $1.209^{*}$ & 0.031 \\
Total FBS & University & Middle school & $3.013^{*}$ & 0.001 \\
& & High school & $1.586^{*}$ & 0.020 \\
\hline
\end{tabular}

OAS: Obesity awareness scale; FBS: Food behaviour scale; ANOVA followed by Scheffe test multiple range test. *significant in $\mathrm{p}<0.05$

preserving and improving health. Imparting the healthy living habits beginning from the childhood period can be attained by means of the nutritional education applications. It is necessary to include the courses of basic nutritional knowledge in the curricula at all stages of the formal education, and to employ the methods such as stories, films, sketches and transferring information during exercise in order to ensure the permanence. Informing the teachers about the cutting-edge innovations in the field of nutrition by means of on-the-job training, educating the families by establishing nutritional training centers in schools, and always taking the triangle of the teacher, the student and the family into consideration will ensure the permanence of the training activities.

No statistically significant differences were found between BMI levels and the subdimensions of the OAS ( $>0.05)$, however a statistically significant difference was found in terms of the food behaviors $(\mathrm{p}<0.05$; Table $7,8)$. This is an indication that they subjects di not change their behaviors whether or not they have awareness about obesity, and that the ones having a normal weight display more correct food behaviors. When the correlation between the food consumption of the children and their weight was investigated, a correlation was found 
Table 7. The results of ANOVA test concerning the effects of the BMI on the OAS and the FBS

\begin{tabular}{llrrrrc}
\hline \multicolumn{1}{c}{ Variables } & Source & df & \multicolumn{1}{c}{ SS } & \multicolumn{1}{c}{ MS } & \multicolumn{1}{c}{ F } & $\mathrm{p}^{*}$ \\
\hline Obesity awareness & Intergroup & 3 & 9.05 & 4.53 & 0.325 & 0.722 \\
& Intragroup & 688 & $9,566.40$ & 13.90 & & \\
Nutirition & Intergroup & 3 & 26.60 & 13.30 & 1.090 & 0.337 \\
& Intragroup & 688 & $8,391.49$ & 12.20 & & \\
Physical activity & Intergroup & 3 & 12.60 & 6.30 & 0.950 & 0.387 \\
& Intragroup & 688 & $4,566.40$ & 6.64 & & \\
FBS total points & Intergroup & 3 & 230.43 & 115.21 & 4.309 & 0.14 \\
& Intragroup & 688 & $18,396.30$ & 26.74 & & \\
\hline
\end{tabular}

SS: Sum of Squares; MS: Mean Square

Table 8. The results of the post-hoc Scheffe test concerning the effects of the BMI on the FBS

\begin{tabular}{|c|c|c|c|c|}
\hline & \multicolumn{2}{|c|}{ BMI } & $\bar{x}$ & $\mathrm{p}^{*}$ \\
\hline Total FBS & Normal & Overweight & $-2.409^{*}$ & 0.041 \\
\hline
\end{tabular}

OAS: Obesity awareness scale; FBS: Food behaviour scale; ANOVA followed by Scheffe test multiple range test. *significant in $\mathrm{p}<0.05$

between the weight and the consumption of lowquality, salty, sugary, fatty foods and sugary and carbonated beverages. The fact that it has been suggested that increasing the consumption of low-fat milk and dairy products, fruit, vegetables and legumes, and having breakfast increases the possibility of being at the normal weight while decreasing the possibility of overweight (Roseman et al. 2007) is in accordance with the findings of the present study, and is of importance in terms of supporting our data.

In recent years, the weight and prevalence of overweight and obesity among children have increased at a global scale. In their systematic review study where the data from 34 countries were evaluated, Jassen et al. (2005) found that, although the rate changed by country, $14.2 \%$ of the children were slightly overweight and $7.7 \%$ were overweight. In Turkey, the prevalence of overweight among children and adolescents is lower compared to other countries. However, the researchers state that the risk factors for overweight are on the increase depending on the changing of lifestyle in the society (Simsek et al. 2008). Preventing weight gain is an easier and cheaper method than treating overweight. Thus, it is of great importance to implement the effective and preventive initiatives intended for children and adolescents. In our sample, the participants having the normal weight constituted the majority, and a great deal of them was engaged in sports as well. Although no difference was found between the participants engaged in sports and those who are not in terms of obesity awareness or food behaviors, the preventive role of sports is apparent and the majority of the children have the normal weight. Thus, the sports programs that children would like should certainly be included in the programs for preventing obesity.

\section{CONCLUSION}

The results showed that there is a positive correlation between the nutritional behaviors and obesity awareness; being or not being engaged in sports does not have an effect in the study subjects' obesity awareness and nutrition behaviour; the nutritional behaviours and obesity awareness are depending on the educational level of the mother and the father and the subjects who have good nutritional behaviors, also have normal BMI.

\section{ACKNOWLEDGEMENT}

Authors would like to thank to all subjects of the study and Uşak Provincial Directorate of National Education that allowed us to use the data of subjects and did the study. The authors have no conflict of interest.

\section{REFERENCES}

Ahrens W, Bammann K, de Henauw S, Halford J, Palou A, Pigeot I, Siani A, Sjostro“m M. 2006. Understanding and preventing child- 
hood obesity and related disorder-IDEFICS: A European multilevel epidemiological approach. Nutr Metab Cardiovasc Dis 16(4):302-308.

Al-Almaie SM. 2005. Prevalence of obesity and overweight among Saudi adolescents in Eastern Saudi Arabia. Saudi Med J 26(4):607-611.

Allen A. 2011. Effects of education al intervention on children's knowledge of obesity risk factors [Phd Thesis]. Montana: Carroll College.

Atkinson RL, Nitzke SA. 2001. School based programmes on obesity: increase knowledge about nutrition but do not change eating habits by much. BMJ 323(7320):10181019.

Barlow SE. 2007. Expert committee recommendations regarding the prevention, assessment, and treatment of child and adolescent overweight and obesity: Summary report. Pediatrics 120(Suppl 4):164-192.

Boumtje PI, Huang CL, Lee JY, Lin BH. 2005. Dietary habits, demographics, and the development of overweight and obesity among children in the United States. Food Policy 30(2):115-128.

Chen YC, Tu YK, Huang KC, Chen PC, Chu DC, Lee YL. 2014. Pathway from central obesity to childhood asthma. Physical fitness and sedentary time are leading factors. Am J Respir Crit Care Med 189(10):11941203.

Cheung PC, Cunningham SA, Narayan KM, Kramer MR. 2016. Childhood obesity incidence in the United States: A Systematic review. Child Obes 12(1):1-11.

Cooke LJ, Wardle J. 2005. Age and gender differences in childre's food preferences. Br J Nutr 93(5):741-746.

Crawford PB, Story M, Wang MC, Ritchie LD, Sabry ZI. 2001. Ethnic issues in the epidemiology of childhood overweight. Pediatr Clin North Am 48(4):855-878.

Demirezen E, Coşansu G. 2005. Adölesan çağ öğrencilerde beslenme alışkanlıklarının değerlendirilmesi. Sted 14(8):174-178.

Demory-Luce D. 2005. Fast food and children and adolescents: implications for practitioners. Clin Pediatr 44(4):279-288.

Döring N, Hansson LM, Andersson ES, Bohman B, Westin M, Magnusson M, Larsson C, Sundblom E, Willmer M, Blennow M, et al. 2014. Primary prevention of childhood obesity through counselling sessions at Swedish child health centres: design, methods and baseline sample characteristics of the PRIMROSE clusterrandomised trial. BM Public Health 14(1):335.

Edmundson E, Parcel GS, Feldman HA, et al. 1996. The effects ofthe child and adolescent trial for cardiovascular health upon psychosocial determinants of diet and physical activity behavior. Prev Med 25(4):442-454.

Galczak-Kondraciuk A, Stempel P, Czeczelewski J. 2018 Assessment of nutritional behaviours of children aged 7-12 attending to primary schools in Biala Podlaska, Poland. Rocz Panstw Zakl Hig. 69(1):71-77.

Gray VB, Byrd SH, Cossman JS, Chromiak J, Cheek WK, Jackson GB. 2007. Family characteristics have limited ability to predict weight status of young children. J Am Diet Assoc 107(7):1204-1209.

Güven A, Odaci H, Özgen ĠT, Bek Y. 2008. Effects of individual factors on adolescent obesity: Study in Turkey. Pediatr Int 50(3):356-362.

Hansson LM, Heitmann BL, Larsson C, Tynelius P, Willmer M, Rasmussen F. 2016. Associations Between Swedish Mothers' and 3- and 5-Year-Old Children's Food Intake. J Nutr Educ Behav 48(8):520-529.

Hern MJ, Gates D, Amlung S, McCabe P. 1998. Linking learning with health behaviors of high school adolescents. Pediatr Nurs 24(2):127-132.

Hood MY, Moore LL, Sundarajan-Ramamurti A, Singer M, Cupples LA, Ellison RC. 2000. Parental eating attitudes and the development of obesity in children, the Framingham children's study. Int J Obes Relat Metab Disord 24(10):1319-1325.

Isabela da Costa $\mathrm{R}$, Taddei JA, Colugnatti $\mathrm{F}$. 2003. Obesity among children attending elementary public schools in São Paulo, Brazil: A case-control study. Public Health Nutr 6(7):659-663.

Janssen I, Katzmarzyk PT, Boyce WF, Vereecken C, Mulvihill C, Roberts C, Currie C, Pickett W. 2005. Health behaviour in school-aged children obesity working group. Comparison of overweight and obesity prevalence in school-aged youth from 34 countries and their relationships with physical activity and dietary patterns. Obes Rev 6(2):123-132.

Kafkas ME, Özen G. 2014. The Turkish Adaptation of the Obesity Awareness Scale: A 
Validity And Reliability Study. Inonu University, Journal of Physical Education and Sport Sciences. 1(2):1-15.

Lakshman R, Mazarello Paes V, Hesketh K, O'Malley C, Moore H, Ong K, Griffin S, van Sluijs E, Summerbell C. 2013. Protocol for systematic reviews of determinants/correlates of obesity-related dietary and physical activity behaviors in young children (preschool 0 to 6 years): Evidence mapping and syntheses. Syst Rev 2(1):28.

Lytle L. 2009. School-based interventions: Where do we go next? Arch Pediatr Adolesc Med 163(4):388-389.

Macaux ALB. 2001. Eat to live or live to eat? Do parents and children agree? Public Health Nutr 4(1A):141-146.

Mirmiran P, Sherafat-Kazemzadeh R, Jalali-Farahani S, Azizi F. 2010. Childhood obesity in the Middle East: a review. East Mediterr Health J 16(9):1009-1017.

Must A, Dallal GE, Dietz WH. 1991. Reference data for obesity: 85 th and 95th percentiles of body mass index (wt/ht2) and triceps skinfold thickness. Am J Clin Nutr 53(4): 839-846.

Newby PK. 2007. Are dietary intakes and eating behaviors related to childhood obesity? A comprehensive review of the evidence. J Law Med Ethics 35(1):35-60.

Novilla ML, Barnes MD, De La Cruz NG, Williams PN, Rogers J. 2006. Public health perspectives on the family: An ecological approach to promoting health in the family and community. Fam Commun Health 29(1):28-42

O'Dea JA, Wilson R. 2006. Socio-cognitive and nutritional factors associated with body mass index in children and adolescents: possibilities for childhood obesity prevention. Health Educ Res 21(6):796-805.

Öztürk M, Erdoğan S. 2010. Çocukların Beslenme Alışkanlıklarının Sağlık Davranışı Etkileşim Modeline Göre İncelenmesi. Istanbul: İstanbul Üniversitesi Sağlık Bilimleri Enstitüsü Doktora Tezi.

Padez C, Mourao I, Moreira P, Rosado V. 2005. Prevalence and risk factors for overweight and obesity in Portuguese children. Acta Paediatr 94(11):1550-1557.

Pérez A, Hoelscher DM, Brown HS, Kelder SH. 2007. Differences in food consumption and meal patterns in texas school children by grade. Prev Chronic Dis 4(2):A23.
Reynolds KD, Baranowski T, Bishop DB, Farris RP, Binkley D, Nicklas TA, Elmer PJ. 1999. Patterns in child and adolescent consumption of fruit and vegetables: Effects of gender and ethnicity across four sites. $\mathrm{J}$ Am Coll Nutr 18(3):248-254.

Rosas LG, Guendelman S, Harley K, Fernald LCH, Neufeld L. Mejia F. Eskenazi B. 2011. Factors associated with overweight and obesity among children of Mexican descent: Results of a binational study. J Immigr Minor Health 13(1):169-180.

Roseman MG, Yeung WK, Nickelsen J. 2007. Examination of weight status and dietary behaviors of middle school students in Kentucky. J Am Diet Assoc 107(7):11391145.

Scaglioni S, Salvioni M, Galimberti C. 2008. Influence of parental attitudes in the development of children eating behaviour. Br J Nutr 99(1):22-25.

Simsek E, Akpinar S, Bahcebasi T, Senses DA, Kocabay K. 2008. The prevalence of overweight and obese children aged 6-17 years in the west black sea region of Turkey. Int J Clin Pract 62(7):1033-1038.

Stock S, Miranda C, Evans S, Plessis S, Ridley J, Yeh S, Chanoine JP. 2007. Healthy buddies: a novel, peer-led health promotion program for the prevention of obesity and eating disorders in children in elementary school. Pediatrics 120(4):1059-1068.

Story M, Lytle LA, Birnbaum AS, Pery CL. 2002. Peer-led, school-based nutrition education for young adolescent: Feasibility and process evaluation of the teens study. J Sch Health 72(3):121-127.

Wardle J, Haase AM, Steptoe A, Nillapun M, Jonwutiwes K, Bellisle F. 2004. Gender differences in food choice: The contribution of health beliefs and dieting. Ann Behav Med 27(2):107-116.

Whitlock EP, O'Connor EA, Williams SB, Beil TL, Lutz KW. 2010. Effectiveness of weight management interventions in children: a targeted systematic review for the USPSTF. Pediatrics 125(2):396-418.

Zaborskis A, Lagunaite R, Busha R, Lubiene J. 2012. Trend in eating habits among Lithuanian school aged children in context of social inequality: three cross-sectional surveys 2002, 2006 and 2010. BMC Public Health 12(1):52. 